\title{
Comparison of extended release GLP-I receptor agonist therapy versus sitagliptin in the management of type 2 diabetes
}

This article was published in the following Dove Press journal:

Diabetes, Metabolic Syndrome and Obesity:Targets and Therapy

21 November 2013

Number of times this article has been viewed

\author{
Mark W Stolar' \\ Michael Grimm² \\ Steve Chen ${ }^{2}$ \\ 'Clinical Medicine, Northwestern \\ University Feinberg School \\ of Medicine, Chicago, IL, USA; \\ ${ }^{2}$ Amylin Pharmaceuticals, LLC, \\ San Diego, CA, USA
}

\begin{abstract}
Exenatide once weekly (EQW), the first glucose-lowering agent for type 2 diabetes that is dosed one time per week, contains exenatide encapsulated in microspheres of a dissolvable matrix, which release active agent slowly and continuously into the circulation following subcutaneous injection. In two direct head-to-head comparisons, EQW resulted in better long-term glucose control, greater reductions in fasting plasma glucose, and more significant weight loss than sitagliptin. In other trials, glucose-lowering effects of EQW compared favorably with those of metformin, pioglitazone, and basal insulin. Patients on EQW exhibited a higher incidence of nausea than those on sitagliptin, although gastrointestinal adverse events occurred primarily during the first 6-8 weeks of therapy and declined thereafter. EQW was also associated with a lower incidence of nausea than two other glucagon-like peptide-1 receptor agonists, exenatide twice daily and liraglutide. Mild hypoglycemic episodes were uncommon with EQW, although risk of hypoglycemia increased in combination with sulfonylureas. When choosing between EQW and a dipeptidyl peptidase-4 (DPP-4) inhibitor, such as sitagliptin, clinicians and patients should consider the differences between the two medications in terms of glucose control (EQW superior to DPP-4 inhibitors), weight control (EQW superior to DPP-4 inhibitors), gastrointestinal tolerability during treatment initiation (EQW inferior to DPP-4 inhibitors), and mode of administration (once-weekly subcutaneous administration versus once-daily oral administration).
\end{abstract}

Keywords: exenatide, glucagon-like peptide 1, dipeptidyl peptidase-4 inhibitors

\section{Introduction}

Managing type 2 diabetes mellitus (T2DM) over the course of a patient's lifetime has proven to be challenging, with less than half of patients at any given time achieving therapeutic goals. ${ }^{1}$ This may be due to many factors, including the advanced state of pancreatic beta-cell dysfunction at the time of diagnosis, the relatively modest efficacy of therapeutic agents to lower blood glucose, and lack of agents that are not only glucose-lowering, but also intrinsically disease-modifying. ${ }^{2-4}$ In addition, numerous challenges surround patient treatment adherence, including cost and tolerability issues. ${ }^{5}$ The discovery and clinical implementation of incretin-based therapies has offered health care providers the opportunity to address a number of intrinsic physiologic defects seen in diabetes and, in the case of glucagon-like peptide-1 (GLP-1) receptor agonist (GLP-1RA) therapy, offer somewhat more efficacious glucose-lowering properties than oral therapeutic alternatives. The development of extended release GLP-1RA therapy may address some of the adherence and side effect issues that have proved to be barriers to therapy in the past.
Correspondence: Mark W Stolar Northwestern Internists, Ltd., 676 North St. Clair Street, Suite 4I5, Chicago, IL 606II, USA

Tel + I 3 | 2335 II 33

Fax +I 3123359774

Email stolar_p@nwinternist.com 
Over 40 years ago, it was discovered that the human insulin response to intravenous glucose was only $30 \%-40 \%$ of that observed after an oral glucose load that raised blood glucose to the same level, indicating that not only blood sugar, but also alimentary mechanisms, regulated insulin secretion. ${ }^{6,7}$ Subsequent studies found that this phenomenon, known as the incretin effect, was attributable in part to a 30-amino-acid hormone known as GLP-1, which is co-encoded with glucagon and is released into circulation from the distal small bowel and colon in response to nutrient ingestion. ${ }^{8,9}$ Upon reaching pancreatic islets, GLP-1 binds to heptahelical G protein-coupled receptors on the membrane of beta cells and stimulates insulin secretion in a glucosedependent fashion, accounting in large part for the observed incretin effect. ${ }^{8}$

Consistent with the wide expression of its receptors in diverse tissues, ${ }^{8,9}$ GLP-1 exhibits biologic activities beyond insulinotropism. In published studies, GLP-1 also inhibited glucagon secretion from pancreatic alpha cells at glucose levels at or above normal fasting levels, reduced gastric motility, and induced feelings of satiety via hunger centers in the hypothalamus. ${ }^{10,11}$ In other studies, direct infusion of GLP-1 modulated fluid intake and increased renal sodium excretion, ${ }^{12,13}$ whereas incretin-based therapy has been associated with blood pressure lowering, beneficial changes in lipid profiles, and improvements in hepatic, myocardial, and endothelial function. ${ }^{14,15}$

Two general classes of incretin therapies have been designed to capitalize on the antihyperglycemic effects of GLP-1. The first, the GLP-1RAs, act by increasing the level of systemic GLP-1 activity. Administered by subcutaneous injection, currently available GLP-1RAs include exenatide twice daily (EBID), ${ }^{16}$ liraglutide once daily, ${ }^{17}$ and exenatide once weekly (EQW). ${ }^{18}$ The dipeptidyl peptidase 4 (DPP-4) inhibitors increase the levels of native GLP-1 by a different mechanism, ie, by inhibiting DPP-4, a widely dispersed and promiscuous protease that normally turns over native GLP-1 rapidly in vivo. ${ }^{19}$ Administered orally, currently available DPP-4 inhibitors include sitagliptin, ${ }^{20}$ saxagliptin, ${ }^{21}$ linagliptin, ${ }^{22}$ and vildagliptin. ${ }^{23}$ All of the preceding incretin agents (GLP-1RAs and DPP-4 inhibitors) have been approved in the United States and the European Union for use in patients with T2DM, with the exception of vildagliptin, which has received marketing authorization in the European Union only.

The purpose of this review is to describe the properties of EQW, the most recently approved incretin therapy and the only antidiabetic agent administered one time per week.
Included here will be a summary of the basic pharmacology, efficacy, and safety of this new long-acting agent, with a particular focus on its comparison to the DPP-4 inhibitor sitagliptin.

\section{Pharmacology of EQW}

Exenatide, the active ingredient in EQW, is a 39-amino-acid synthetic version of exendin-4, a peptide isolated from the lizard Heloderma suspectum that shares approximately 50\% sequence identity with human GLP-1. ${ }^{24}$ Exenatide binds with high affinity to GLP-1 receptors and has all of the known glucoregulatory activities of GLP-1. ${ }^{25-27}$ However, it is more resistant than GLP-1 to degradation by DPP- $4 .{ }^{24}$ In the twicedaily formulation, median peak plasma concentrations of exenatide occurred 2.1 hours after administration, and the subsequent mean terminal half-life was 2.4 hours, ${ }^{16}$ pharmacokinetic parameters that permitted twice-daily administration before the two main meals of the day.

In the new once-weekly formulation, exenatide has been encapsulated in injectable microspheres that degrade in situ after administration and slowly release drug into circulation in a sustained fashion. ${ }^{28}$ The structural matrix of the microsphere is composed of a medical-grade biodegradable polymer called poly-(d,l-lactide-co-glycolide) (PLG), which has been used in dissolvable surgical sutures, bone plates, and orthopedic implants for decades and in microsphere form as a long-acting drug-delivery system since $1984 .{ }^{29-31}$ Degradation of the PLG polymer occurs by hydrolysis of the ester linkages into lactic acid and glycolic acid, which are easily eliminated as carbon dioxide and water. It is important to note that the encapsulated exenatide in EQW, as well as the active agent released into circulation, is identical to that in EBID.

In a pharmacokinetic study on patients with T2DM receiving a single dose of EQW, exposure increased with dose (2.5, 5,7 , or $10 \mathrm{mg}$ ), with measurable levels of exenatide lasting for up to 10 weeks. ${ }^{32}$ The same study evaluated exenatide exposure following once-weekly administrations of EQW $0.8 \mathrm{mg}$ or EQW $2.0 \mathrm{mg}$ in 45 patients with T2DM across a 15-week treatment period (Figure 1). ${ }^{32}$ In patients who received the $2.0 \mathrm{mg}$ dose, the currently indicated dosage, ${ }^{18}$ plasma exenatide concentrations rose over time and reached steady-state levels by approximately 6-7 weeks. At steady state, overall plasma levels were roughly comparable to the maximum concentration reached after a single injection of EBID.

\section{Efficacy of EQW versus sitagliptin}

Six randomized controlled trials, known by the acronym DURATION for Diabetes Therapy Utilization: Researching 


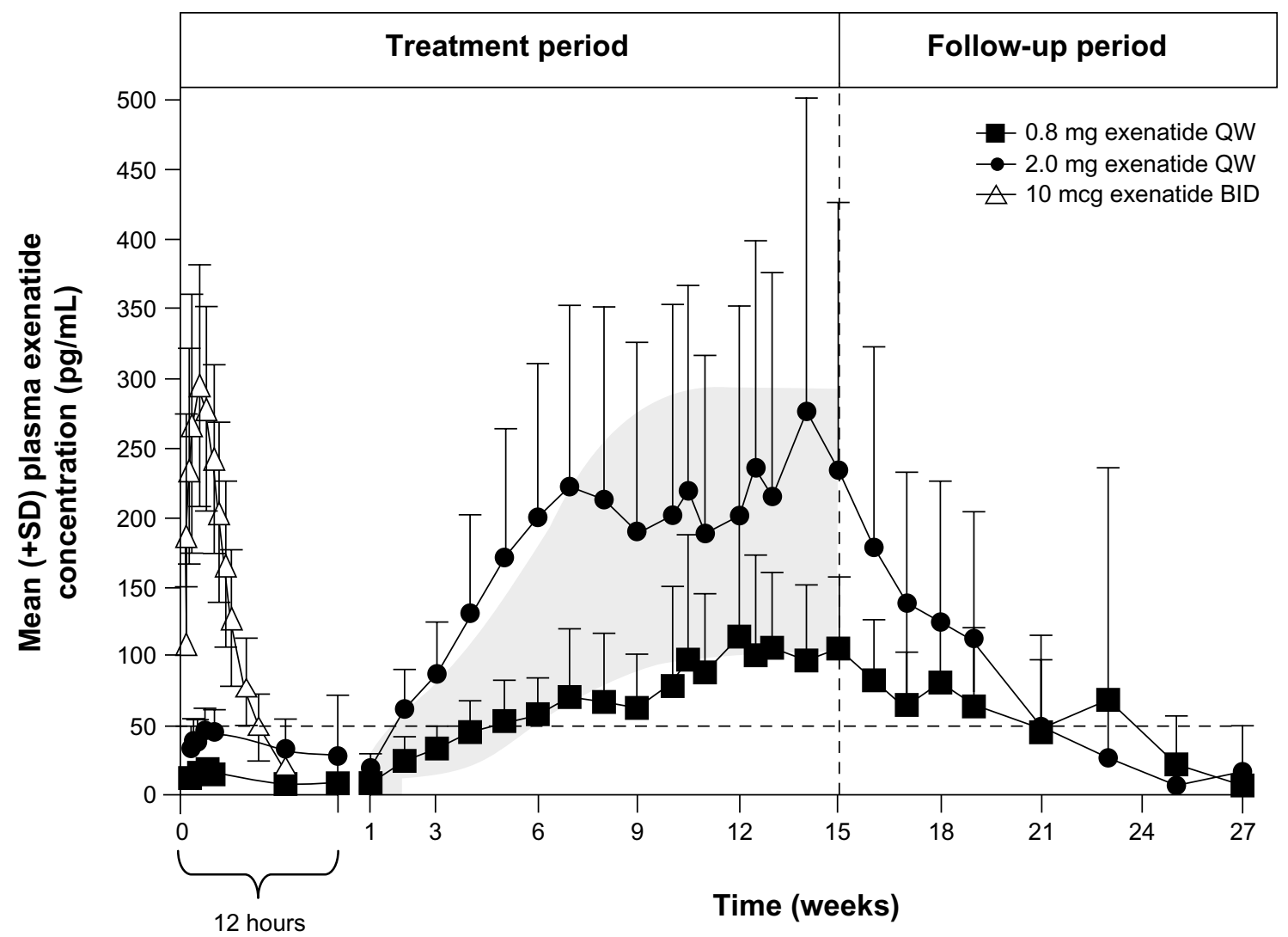

Figure I Pharmacokinetics of EQW. Plasma exenatide concentrations following a single dose of EBID ( $n=39)$ and multiple doses of EQW ( $n=3 I)$.

Notes: Shading represents exenatide blood level predictions for $2 \mathrm{mg}$ (top boundary) and $0.8 \mathrm{mg}$ (bottom boundary) weekly repeating EQW administrations with the use of superpositioning of single-dose data. The vertical dashed line shows the end of the EQW dosing period in the trial. The horizontal line is the minimally effective level of exenatide demonstrated to reduce fasting plasma glucose concentrations. ${ }^{58}$

Modified from Fineman et al. With kind permission from Springer Science+Business Media: Clin Pharmacokinet, Pharmacokinetics and pharmacodynamics of exenatide extended-release after single and multiple dosing, 201 I;50(I):65-74, Fineman M, Flanagan S, Taylor K, et al., figure 2.32

Abbreviations: BID, twice daily; EBID, exenatide twice daily; EQW, exenatide once weekly; QW, once weekly; SD, standard deviation.

Changes in A1c, Weight and Other Factors Through Intervention with Exenatide Once Weekly, have been conducted to determine the efficacy and safety profiles of EQW (Table 1). ${ }^{33-38}$ DURATION $-4^{37}$ and DURATION-233 directly compared EQW with the DPP-4 inhibitor sitagliptin.

\section{EQW monotherapy versus sitagliptin monotherapy}

DURATION-4 compared EQW monotherapy ( $\mathrm{n}=248$ ) versus sitagliptin monotherapy $(\mathrm{n}=163)$ in drug-naïve patients who needed to intensify their diet and exercise therapy (the trial also included a metformin arm and a pioglitazone arm, see below) (Figure 2). ${ }^{37}$ After 26 weeks of therapy, mean glycated hemoglobin $\left(\mathrm{HbA}_{1 \mathrm{c}}\right)$ levels decreased to $6.94 \%$ with EQW (mean change, $-1.53 \%$ ) and $7.32 \%$ with sitagliptin (mean change, $-1.15 \% ; P<0.001)$. Significantly more patients treated with EQW than sitagliptin achieved $\mathrm{HbA}_{1 \mathrm{c}}<7.0 \%$ (63\% versus $43 \%, P<0.001)$ and $\leq 6.5 \%$ ( $49 \%$ versus $26 \%$; $P<0.001)$. Reductions in fasting plasma glucose (FPG) were also significantly greater in the EQW group $(-41.4 \mathrm{mg} / \mathrm{dL}$ versus $-19.8 \mathrm{mg} / \mathrm{dL} ; P<0.001)$. Finally, in seven-point selfmonitored blood glucose profiles, EQW was associated with greater mean reductions compared with sitagliptin $(P<0.05$ at all time points).

In addition to glycemic parameters, DURATION-4 evaluated other patient outcomes. ${ }^{37}$ After 26 weeks of therapy, mean weight changed from baseline by $-2.0 \mathrm{~kg}$ in the EQW group compared with $-0.8 \mathrm{~kg}$ in the sitagliptin group $(P<0.001)$ (Figure 2). Beta-cell function, as measured by geometric mean homeostasis model assessment (HOMA)-B (C-peptide), improved more with EQW than sitagliptin $(P<0.001)$. Changes in insulin sensitivity, as measured by HOMA-S (C-peptide), were similar in the two treatment groups.

\section{EQW versus sitagliptin as add-on therapy to metformin}

DURATION-2 compared EQW ( $\mathrm{n}=160)$ with sitagliptin $(n=166)$ in patients with T2DM who needed to intensify metformin monotherapy (pioglitazone was also a comparator 
Table I Summary of EQW outcomes in the DURATION study program

\begin{tabular}{|c|c|c|c|c|c|c|}
\hline & DURATION-4 ${ }^{37}$ & DURATION-2 ${ }^{33}$ & DURATION-I ${ }^{36}$ & DURATION-5 ${ }^{34}$ & DURATION-6 ${ }^{38}$ & DURATION-3 ${ }^{35}$ \\
\hline Background therapy & $\mathrm{D} / \mathrm{E}$ alone & MET & \multicolumn{3}{|c|}{$\mathrm{D} / \mathrm{E}$ alone $\pm \mathrm{MET}, \mathrm{SFU}$, or TZD (or combos) } & $\mathrm{MET} \pm \mathrm{SFU}$ \\
\hline EQW & $2 \mathrm{mg}$ QW & $2 \mathrm{mg}$ QW & $2 \mathrm{mg}$ QW & $2 \mathrm{mg}$ QW & $2 \mathrm{mg}$ QW & $2 \mathrm{mg}$ QW \\
\hline \multirow[t]{3}{*}{ Comparator(s) } & MET & SITA (I00 mg QD) & EBID & EBID & Liraglutide & GLAR \\
\hline & $\mathrm{PIO}$ & $\mathrm{PIO}$ (45 mg QD) & 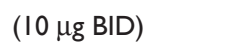 & $(10 \mu g$ BID) & (I.8 mg QD) & $(10 \mathrm{IU} Q D)^{\mathrm{a}}$ \\
\hline & SITA & & & & & \\
\hline Design & DBDD & DBDD & OL & OL & OL & OL \\
\hline Duration (weeks) & 26 & 26 & 30 & 24 & 26 & 26 \\
\hline ITT population $(\mathrm{N})^{\mathrm{b}}$ & 248 & 160 & 148 & 129 & 911 & 233 \\
\hline \multicolumn{7}{|l|}{$\mathrm{HbA}_{\mathrm{Ic}}(\%)$} \\
\hline Baseline & 8.5 & 8.6 & 8.3 & 8.5 & 8.5 & 8.3 \\
\hline LS mean change & -1.5 & -1.5 & -1.9 & -1.6 & -1.3 & -1.5 \\
\hline \multicolumn{7}{|l|}{$\mathrm{HbA}_{\mathrm{Ic}}$ targets (\%) } \\
\hline$<7.0 \%$ & 63 & 59 & 71 & 58 & 52.3 & 60 \\
\hline$\leq 6.5 \%$ & 49 & 39 & 45 & 41 & 31 & 35 \\
\hline \multicolumn{7}{|l|}{ FPG $(\mathrm{mg} / \mathrm{dL}[\mathrm{mmol} / \mathrm{L}])$} \\
\hline Baseline & I78.2 (9.9) & $165.6(9.2)$ & I $72.8(9.6)$ & $172.8(9.6)$ & $172.8(9.6)$ & I $78.2(9.9)$ \\
\hline LS mean change & $-4 I .4(-2.3)$ & $32.4(-1.8)$ & $-4 I .4(-2.3)$ & $-34.2(-1.9)$ & $-32.4(-1.8)$ & $-37.8(-2.1)$ \\
\hline \multicolumn{7}{|l|}{ Weight (kg) } \\
\hline Baseline & 88 & 89.9 & 101.7 & 97 & 91 & 91.2 \\
\hline LS mean change & -2.0 & -2.3 & -3.7 & -2.3 & -2.7 & -2.6 \\
\hline \multicolumn{7}{|l|}{ SBP $(\mathrm{mmHg})$} \\
\hline Baseline & 128.8 & 126.4 & 127.8 & 130.4 & 132 & 135.4 \\
\hline LS mean change & -1.3 & -3.6 & -4.7 & -2.9 & -2.5 & -3.0 \\
\hline
\end{tabular}

Notes: adjusted to target FPG of $4.0-5.5 \mathrm{mmol} / \mathrm{L}$; '

Abbreviations: DBDD, double-blind double-dummy; D/E, diet and exercise; EBID, exenatide twice daily; EQW, exenatide once weekly; FPG, fasting plasma glucose; GLAR, insulin glargine; $\mathrm{HbA}_{1}$, glycated hemoglobin; ITT, intent to treat; LS, least squares; MET, metformin; OL, open-label; PIO, pioglitazone; QW, once weekly; SBP, systolic blood pressure; SITA, sitagliptin; SFU, sulfonylurea; TZD, thiazolidinedione; DURATION, Diabetes Therapy Utilization: Researching Changes in AIc, Weight and Other Factors Through Intervention with Exenatide Once Weekly; QD, once daily; BID, twice daily.

in the trial, see below) (Figure 2). ${ }^{33}$ After 26 weeks of therapy, mean changes from baseline in $\mathrm{HbA}_{1 \mathrm{c}}$ were $-1.5 \%$ with $\mathrm{EQW}$ and $-0.9 \%$ with sitagliptin $(P<0.0001)$. Significantly more patients on EQW than sitagliptin achieved $\mathrm{HbA}_{1 \mathrm{c}}$ targets of $<7.0 \%$ and $\leq 6.5 \%$ ( $P<0.0001$ for both comparisons), and EQW reduced FPG significantly more than sitagliptin $(-32.4 \mathrm{mg} / \mathrm{dL}$ versus $-16.2 \mathrm{mg} / \mathrm{dL} ; P=0.0038)$. In all measurements on a six-point self-monitored blood glucose profile, reductions at week 26 were significantly greater with EQW than sitagliptin $(P<0.05$ at all measurements). Weight loss with exenatide $(-2.3 \mathrm{~kg})$ was significantly greater than with sitagliptin $(-0.8 \mathrm{~kg} ; P=0.0002)$.

A 26-week, open-label extension of DURATION-2 evaluated the safety and efficacy of continued EQW therapy, as well as the outcome of switching from sitagliptin to EQW. ${ }^{39}$ Patients in the EQW $\rightarrow$ EQW population maintained the significant improvements in long-term blood glucose control at 52 weeks that were observed in the original study at 26 weeks (change from baseline in $\mathrm{HbA}_{1 \mathrm{c}},-1.6 \%$; change in $\mathrm{HbA}_{1 \mathrm{c}}$ after the switch, $+0.06 \%$ ); weight remained significantly below baseline after 52 weeks of therapy $(-1.8 \mathrm{~kg} ; P=0.0002$ versus the original baseline), but increased relative to the 26-week time point $(+0.7 \mathrm{~kg})$. Patients in the sitagliptin $\rightarrow$ EQW population demonstrated significant incremental improvements in both $\mathrm{HbA}_{1 \mathrm{c}}(-0.3 \%$ after the switch; $P=0.0010)$ and weight ( $-1.1 \mathrm{~kg}$ after the switch; $P=0.0006)$.

\section{EQW versus other antidiabetic agents}

EQW also compared favorably with other antidiabetic agents in its glucose-lowering and weight-sparing effects (Figure 3). For instance, compared with EBID in DURATION-1, patients on EQW exhibited a larger mean reduction from baseline in $\mathrm{HbA}_{1 \mathrm{c}}(-1.9 \%$ versus $-1.5 \% ; P=0.0023)$, a higher proportion of patients reaching target $\mathrm{HbA}_{1 \mathrm{c}} \leq 7 \%$ (77\% versus $61 \%$; $P=0.0039)$, and a larger mean reduction in FPG $(-41.4 \mathrm{mg} / \mathrm{dL}$ versus $-25.2 \mathrm{mg} / \mathrm{dL} ; P<0.00001)$. Patients receiving EBID, on the other hand, had significantly greater improvements in 2-hour postprandial plasma glucose excursions $(-124.2 \mathrm{mg} / \mathrm{dL}$ versus $-95.4 \mathrm{mg} / \mathrm{dL} ; P=0.00123) .{ }^{36}$ Similar weight loss was observed with both agents. ${ }^{36}$ DURATION-5 also compared EQW with EBID, and EQW was associated with significantly greater changes from baseline in $\mathrm{HbA}_{1 \mathrm{c}}$ $(-1.6 \%$ versus $-0.9 \% ; P<0.0001)$ and FPG $(-35 \mathrm{mg} / \mathrm{dL}$ versus $-12 \mathrm{mg} / \mathrm{dL} ; P<0.0008)$ and similar reductions in mean bodyweight $(-2.3$ and $-1.4 \mathrm{~kg}){ }^{34}$ 

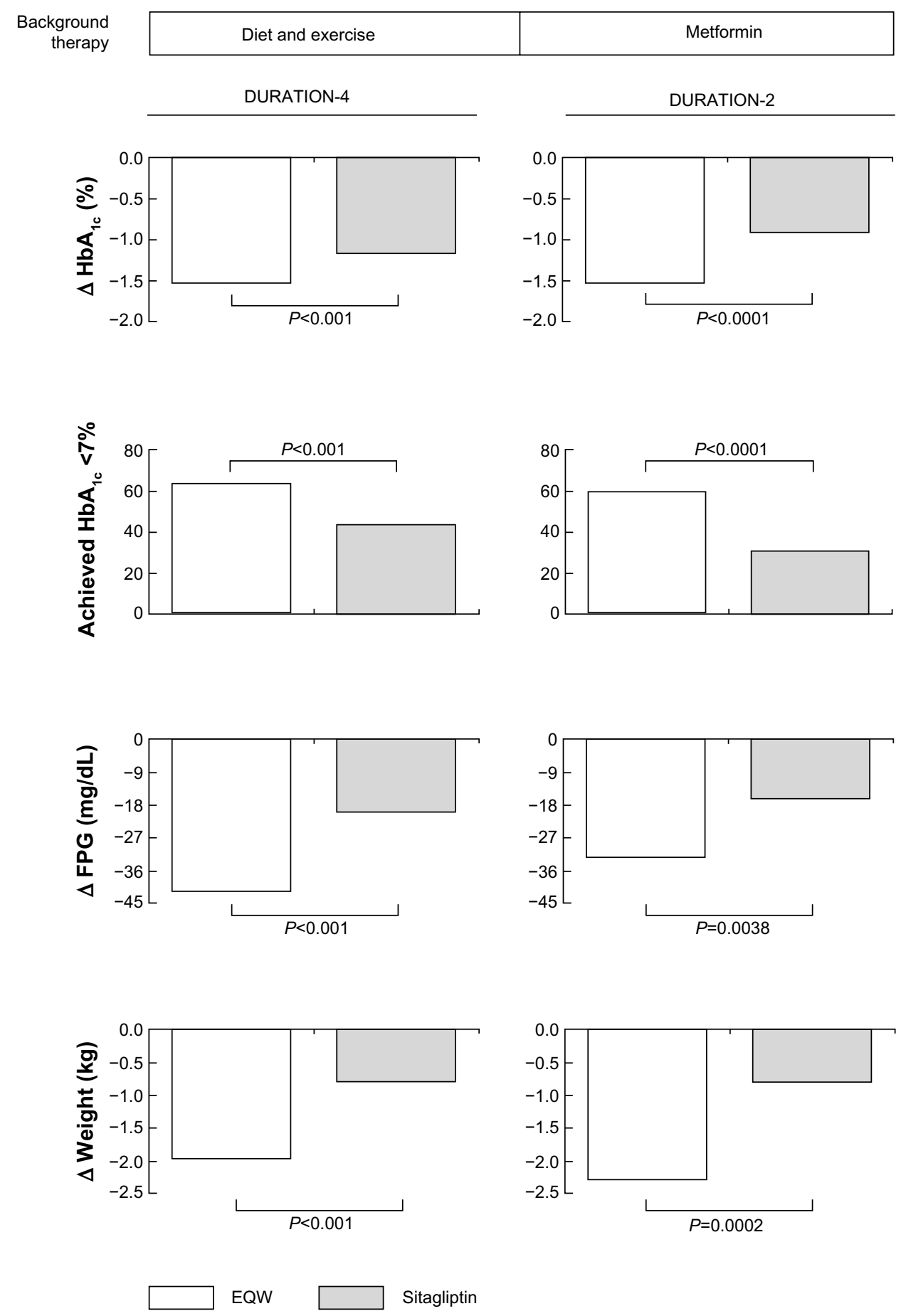

Figure 2 Effects of EQW on glycemia and weight relative to sitagliptin in the DURATION study program.

Abbreviations: EQW, exenatide once weekly; FPG, fasting plasma glucose; HbA in Alc, Weight and Other Factors Through Intervention with Exenatide Once Weekly.

Other comparators in the DURATION trials included metformin, pioglitazone, insulin glargine, and liraglutide. In patients on diet and exercise background therapy, EQW, metformin, and pioglitzaone reduced $\mathrm{HbA}_{1 \mathrm{c}}$ to similar extents, whereas in patients on metformin background therapy, EQW reduced $\mathrm{HbA}_{\mathrm{lc}}(-1.5 \%)$ significantly more than pioglitazone $(-1.2 \% ; P=0.017) .{ }^{33}$ In patients on oral antidiabetic agent combination therapy, EQW reduced $\mathrm{HbA}_{1 \mathrm{c}}$ significantly more than insulin glargine $(-1.5 \%$ versus $-1.3 \% ; P<0.05),{ }^{35}$ but significantly less than liraglutide $(-1.3 \%$ versus $-1.5 \%$; $P<0.05) .{ }^{38} \mathrm{EQW}$ therapy was associated with moderate weight loss in all of the DURATION trials; pioglitazone and insulin glargine use were associated with weight gain (Figure 3). 


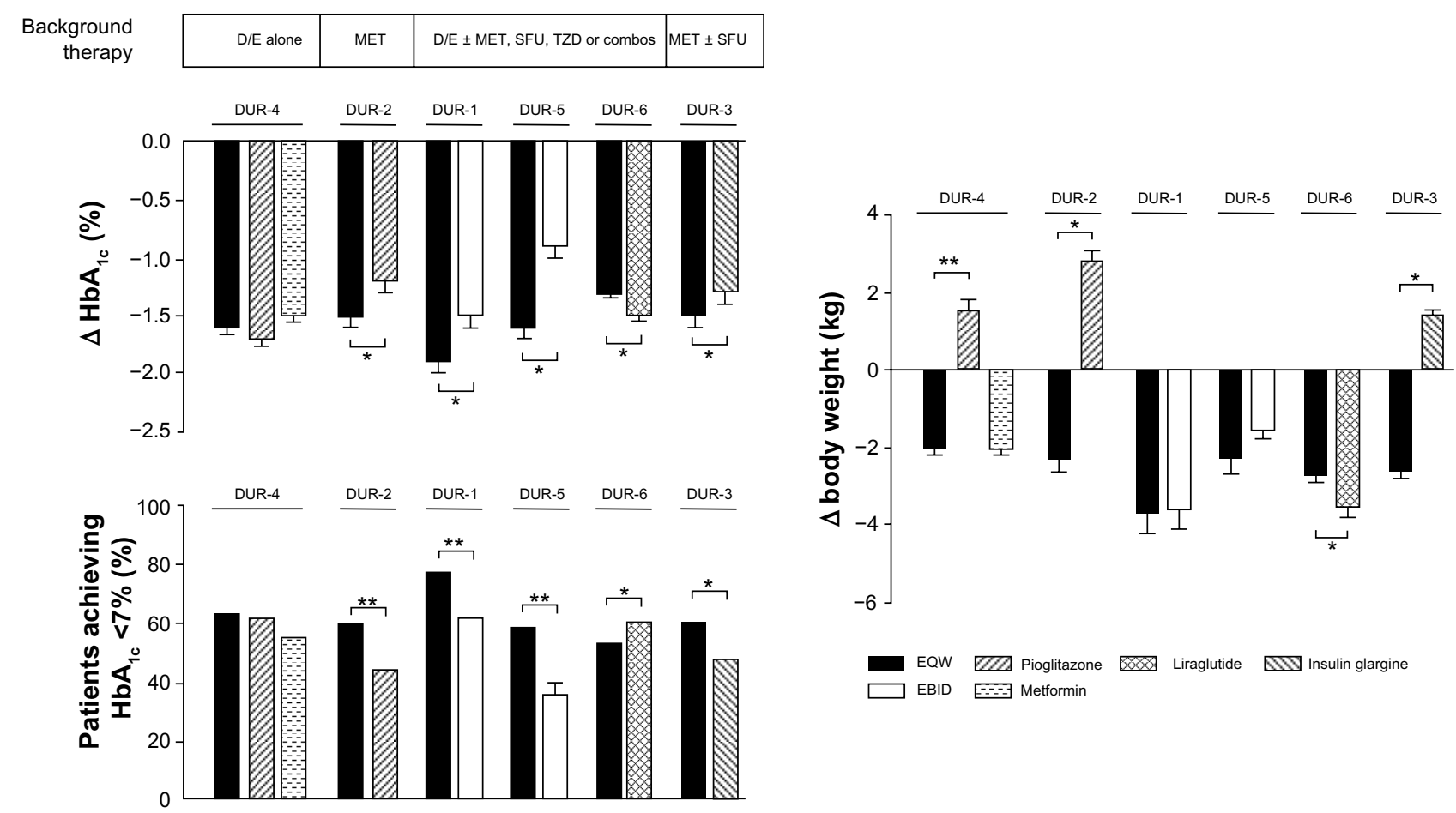

Figure 3 Effects of EQW on glycemia and weight relative to comparators in the DURATION trials. Notes: Data are mean \pm SE. $* P<0.05 ; * * P<0.001$.

Abbreviations: D/E, diet and exercise; EBID, exenatide twice daily; EQW, exenatide once weekly; HbA, glycated hemoglobin; MET, metformin; SFU, sulfonylurea; TZD, thiazolidinedione; DURATION, Diabetes Therapy Utilization: Researching Changes in Alc, Weight and Other Factors Through Intervention with Exenatide Once Weekly.

\section{Safety and tolerability of EQW Gastrointestinal side effects}

Nausea was the most commonly reported gastrointestinal adverse event in patients on GLP-1RAs in the DURATION study program (Table 2). For EQW, reported events of nausea occurred predominantly in the first 6-8 weeks of therapy, ${ }^{28}$

Table 2 Rates of gastrointestinal adverse events associated with incretin therapies in the DURATION study program

\begin{tabular}{lllll}
\hline & $\begin{array}{l}\text { Nausea } \\
\text { (\%) }\end{array}$ & $\begin{array}{l}\text { Diarrhea } \\
\text { (\%) }\end{array}$ & $\begin{array}{l}\text { Vomiting } \\
(\%)\end{array}$ & $\begin{array}{l}\text { Constipation } \\
\text { (\%) }\end{array}$ \\
\hline DURATION-I & & & & \\
EQW & 26.4 & 13.5 & 10.8 & 10.8 \\
EBID & 34.5 & 13.1 & 18.6 & 6.2 \\
DURATION-2 & & & & \\
EQW & 24 & 18 & 11 & 6 \\
$\quad$ Sitagliptin & 10 & 10 & 2 & 2 \\
$\begin{array}{l}\text { DURATION-4 } \\
\text { EQW }\end{array}$ & 11.3 & 10.9 & $\mathrm{NR}$ & 8.5 \\
$\quad$ Sitagliptin & 3.7 & 5.5 & $\mathrm{NR}$ & 2.5 \\
$\begin{array}{l}\text { DURATION-5 } \\
\text { EQW }\end{array}$ & 14.0 & 9.3 & 4.7 & $\mathrm{NR}$ \\
EBID & 35.0 & 4.1 & 8.9 & $\mathrm{NR}$ \\
DURATION-6 & & & & \\
EQW & 9.3 & 6.1 & 3.7 & 4.6 \\
Liraglutide & 20.7 & 13.1 & 10.7 & 4.9 \\
\hline
\end{tabular}

Abbreviations: EBID, exenatide twice daily; EQW, exenatide once weekly; NR, not reported; DURATION, Diabetes Therapy Utilization: Researching Changes in Alc, Weight and Other Factors Through Intervention with Exenatide Once Weekly. consistent with studies showing that gastrointestinal adverse events occurred more commonly during initiation of EBID than later in therapy. ${ }^{40}$ Other gastrointestinal adverse events that occurred in the DURATION trials at higher rates with EQW than non-incretin therapy comparators included diarrhea, vomiting, and constipation. In direct head-to-head comparisons, EQW was associated with less nausea than either EBID or liraglutide, and more nausea than sitagliptin. The greater gastrointestinal tolerability of EQW relative to other GLP-1-RAs may reflect the more gradual rise in blood exenatide concentrations after initiating EQW therapy (Figure 1). ${ }^{41}$

\section{Hypoglycemia}

No episodes of major hypoglycemia were documented in patients on EQW in any of the DURATION trials. ${ }^{33-38}$ In a pooled analysis of all DURATION studies (Amylin Pharmaceuticals, data on file, 2013), the incidence of minor hypoglycemia (defined as a plasma glucose concentration $<54 \mathrm{mg} / \mathrm{dL}$ ) in patients who received EQW as monotherapy or in combination with metformin or thiazolidinediones was $2.0 \%$. Sitagliptin therapy was associated with a similarly low rate of hypoglycemic episodes in the DURATION trials $(1.5 \%)$. When EQW was used in combination with 
sulfonylureas, however, the incidence of mild hypoglycemia increased to $15.7 \%$.

\section{Cardiovascular risk}

A randomized double-blind study found that exenatide administered at therapeutic and supratherapeutic concentrations did not produce a clinically significant change in the QT interval..$^{42}$ Another study ${ }^{43}$ examined 148 patients with T2DM who had been treated with EQW and found that the change in QT interval corrected for heart rate using Fridericia's formula (QTcF) was small and clinically insignificant after 14 weeks (1.7 milliseconds) and 30 weeks (3.0 milliseconds) of therapy. No patient had a QTcF interval during treatment that exceeded 450 milliseconds or a $\Delta \mathrm{QTcF}>60$ milliseconds. Similar results were found after a single dose of EBID. ${ }^{44}$

EQW use over periods of $>6$ months has shown small favorable effects on cardiovascular risk factors and biomarkers. For instance, patients treated with EQW in the 30-week DURATION-1 study who continued open-label treatment to 52 weeks had significant reductions from baseline in systolic blood pressure (SBP) $(-6.2 \mathrm{mmHg} ; 95 \%$ confidence interval [CI], -8.5 to $-3.9 \mathrm{mmHg}$ ), whereas $50 \%$ of those with baseline $\mathrm{SBP} \geq 130 \mathrm{mmHg}$ were observed to have lowered their SBP to normal. ${ }^{45}$ The decreases in SBP were not due to changes in antihypertensive therapy, as $84 \%$ of patients who completed the study had not modified their antihypertensive therapy. ${ }^{45}$ Total cholesterol and low-density lipoprotein cholesterol also decreased significantly for EQW-treated patients in DURATION-1 and DURATION-5. ${ }^{34,36}$ Triglycerides in EQW-treated patients decreased in both studies, as well, with significant changes observed in the 30 -week study.

\section{Pancreatic risk}

A recent study examined the US Food and Drug Administration's Adverse Event Reporting System and found an increased incidence of pancreatitis in patients on EBID or sitagliptin compared with patients on other therapies ${ }^{46}$ although potential problems associated with using spontaneous reporting as the basis for determining event rates has received comment. ${ }^{47}$ Different results were obtained in an analysis of a large health insurance transaction database, which found that the absolute risk of acute pancreatitis among exenatide and sitagliptin initiators was $0.13 \%$ (37 cases among 27,996 patients) and $0.12 \%$ (19 cases among 16,267 patients), respectively; these rates were equivalent to the absolute risk in a propensity score-matched cohort of metformin/glyburide initiators. ${ }^{48}$ Furthermore, in a recent integrated safety analysis of pooled data from 19 completed randomized controlled trials, composite exposure-adjusted incidence rates for pancreatitis among EBID users $(n=3,261)$ and the pooled comparator group $(n=2,333)$ were not statistically different. ${ }^{40}$ The current package insert recommends that EQW be discontinued immediately if pancreatitis is suspected and that other antidiabetic therapies may be considered in patients with a history of pancreatitis. ${ }^{18}$

The prior Adverse Event Reporting System study also found an increased rate of spontaneously reported pancreatic cancer in patients on EBID compared with patients on other therapies ${ }^{46}$ To date, though, the results of prospective or longitudinal studies that evaluated pancreatic cancer incidence rates in patients on EQW (or EBID or liraglutide) versus other antidiabetic agents have not been reported. In general terms, the American Diabetes Association recommends that cancer risk should not be a major factor in choosing between available diabetes therapies for the average patient, although the choice of therapy for patients with a very high cancer risk or recurrence of specific cancer types may require more careful consideration. ${ }^{49}$

\section{Thyroid risk}

In rats and mice, sustained activation of GLP-1 receptors on thyroid $\mathrm{C}$ cells increased calcitonin secretion, $\mathrm{C}$-cell hyperplasia, and medullary thyroid cancer. ${ }^{50}$ In humans, however, GLP-1RA use did not substantially raise calcitonin levels, and an analysis of sequential changes in calcitonin levels in several thousand diabetic subjects did not reveal a relationship between liraglutide therapy and plasma calcitonin. ${ }^{50,51}$ In the meta-analysis described above on 3,261 EBID users and 2,333 pooled comparator users (mean exposure time, 166-171 days), ${ }^{40}$ occurrences of thyroid neoplasm were benign and very rare; the exposure-adjusted incidence rate of any thyroid neoplasm was 0.3 per 100 patient-years with exenatide compared with no occurrences of thyroid neoplasm with placebo/insulin (overall risk difference, 0.27; 95\% CI, $0.01-0.53)$. Although cancer of the thyroid is very rare (incidence of approximately 12 per 100,000 persons in the $\mathrm{US}^{16}$ ), the use of EQW in patients with a personal or family history of medullary thyroid carcinoma or multiple endocrine neoplasia syndrome type 2 is contraindicated. ${ }^{18}$

\section{Renal side effects}

There have been post-marketing reports of altered renal function with exenatide, including increased serum creatinine, renal impairment, worsened chronic renal failure, and acute renal failure, sometimes requiring hemodialysis or kidney transplantation. ${ }^{18}$ Some of these events occurred in patients 
receiving one or more pharmacologic agents known to affect renal function or hydration status, and some occurred in patients who had been experiencing nausea, vomiting, or diarrhea, with or without dehydration. Reversibility of altered renal function has been observed in many cases with supportive treatment and discontinuation of potentially causative agents. Exenatide has not been found to be directly nephrotoxic in preclinical or clinical studies.

\section{Other investigational approaches for reducing the frequency of exenatide administration}

Given the positive outcomes of EQW studies, it is of interest to assess the clinical utility of even longer-acting preparations. Two other investigational agents have been described that allow for lower frequency of exenatide dosing. The first was a new once-monthly formulation, consisting of EQW microspheres reconstituted in a triglyceride-based diluent. ${ }^{52}$ Improved patient adherence may be a potential benefit of exenatide once monthly (EQM), owing to greater convenience of administration, ${ }^{53,54}$ although this advantage remains unproven and will require prospective Phase III trials for confirmation. A preliminary open-label controlled study evaluated the safety and efficacy of $\operatorname{EQM}(5,8$, or $11 \mathrm{mg})$ versus EQW in 121 patients with T2DM on diet/exercise, metformin, pioglitazone, or metformin plus pioglitazone. ${ }^{52}$ Across a 20-week treatment period, $\mathrm{HbA}_{1 \mathrm{c}}$ decreased in the EQM 5, 8 , and $11 \mathrm{mg}$ groups by $-1.3 \%,-1.3 \%$, and $-1.5 \%$, respectively (EQW control, $-1.5 \%$ ), and the percentages of patients achieving $\mathrm{HbA}_{1 \mathrm{c}}<7 \%$ were $50 \%, 57 \%$, and $70 \%$, respectively (EQW control, 48\%). EQM therapy was also associated with improvements in FPG $(-25,-30$, and $-49 \mathrm{mg} / \mathrm{dL}$, respectively) and weight $(-1.1,-0.4$, and $-1.1 \mathrm{~kg}$, respectively). No unique safety findings were observed with EQM relative to EQW. The most frequent adverse events for EQM were headache $(17 \%-27 \%)$ and nausea $(17 \%-23 \%)$. No major or minor hypoglycemia was observed in any treatment group.

Another form of exenatide delivery was evaluated in a Phase II study with ITCA 650, a subcutaneous osmotic delivery system that provides for continuous delivery of exenatide at specified doses for 3 months. A 48-week study evaluated ITCA 650 at 4 doses $(20,40,60$, and $80 \mu$ g per day) in patients with T2DM. ${ }^{55}$ After 48 weeks at the chronic dose selected for further Phase III studies (60 $\mu \mathrm{g}$ per day), mean $\mathrm{HbA}_{1 \mathrm{c}}$ levels decreased from baseline by $1.5 \%$, $78 \%$ of patients had $\mathrm{HbA}_{1 \mathrm{c}}$ levels $\leq 7 \%$, and mean weight declined by $3.5 \mathrm{~kg}$. Overall, the treatment appeared to be well tolerated.

\section{Conclusion}

EQW is the first approved medication for T2DM that is administered one time per week. In direct head-to-head comparisons, EQW resulted in better glucose control $\left(\mathrm{HbA}_{1 \mathrm{c}}\right)$, higher proportions of patients reaching treatment goals, greater reductions in FPG, and more significant weight loss than the DPP-4 inhibitor sitagliptin. To date, the primary limiting factor for GLP-1RA use has been gastrointestinal adverse events, notably nausea, vomiting, diarrhea, and constipation. EQW, however, was associated with less nausea than either EBID or liraglutide, but more than sitagliptin. The incidence of mild hypoglycemia in patients who received EQW as monotherapy or in combination with metformin or thiazolidinediones was low, although it was higher in patients who received concomitant treatment with a sulfonylurea.

A recent position statement from the American Diabetes Association and the European Association for the Study of Diabetes recommended maintaining $\mathrm{HbA}_{1 \mathrm{c}}$ below $7 \%$ as a general treatment goal in patients with T2DM, but emphasized individualization of therapy rather than a rigid stepcare approach. ${ }^{56}$ The clinical utility of EQW is intriguing when looked at from the perspective of this new treatment paradigm in that it allows for earlier use of EQW in patients with diabetes, significant obesity, and issues with both dietary compliance and postprandial glycemic control.

Although many physicians may still view DPP-4 inhibitors as equivalent to injectable GLP-1RAs, both postprandial and overall glycemic control was significantly better on EQW therapy in clinical trials. Time and teaching barriers to any injectable therapy may lead many patients to favor an oral therapy, but it should be noted that administration of EQW requires only one additional step than other common injectable diabetes medications, ie, suspension of the microspheres before administration, and that a published study showed a majority of patients were capable of independently selfadministering a microsphere preparation. ${ }^{57}$

Regarding other therapies, early use of EQW may be hindered by the impending availability of less costly generic thiazolidinediones, as well as metformin and sulfonylureas. However, exenatide in combination with metformin or with metformin plus pioglitazone, as suggested by DeFronzo, ${ }^{3}$ may possibly address physiologic defects seen in diabetes more effectively than alternative combinations. The ability to modify postprandial glycemic excursions with a onceweekly shot rather than multiple doses of insulin may also have added benefits in patient compliance and reduced hypoglycemia. 


\section{Author contributions}

All authors contributed toward the interpretation of data, writing of the manuscript and approving the final version.

\section{Acknowledgments}

Amylin Pharmaceuticals, LLC, provided funding for this study. The authors would like to thank David Norris, PhD, of Ecosse Medical Communications (Falmouth, MA) and Steve Brunell, PhD, of Amylin Pharmaceuticals for editorial assistance provided during the preparation of the manuscript.

\section{Disclosure}

MWS is a member of an advisory board and the Speakers Bureau for Takeda Pharmaceuticals. SC and MG were employees of Amylin Pharmaceuticals, LLC, when this manuscript was drafted.

\section{References}

1. Koro CE, Bowlin SJ, Bourgeois N, Fedder DO. Glycemic control from 1988 to 2000 among US adults diagnosed with type 2 diabetes: a preliminary report. Diabetes Care. 2004;27(1):17-20.

2. DeFronzo RA. Lilly Lecture 1987 . The triumvirate: beta-cell, muscle, liver. A collusion responsible for NIDDM. Diabetes. 1988;37(6): 667-687.

3. DeFronzo RA. Banting Lecture. From the triumvirate to the ominous octet: a new paradigm for the treatment of type 2 diabetes mellitus. Diabetes. 2009;58(4):773-795.

4. Kendall DM, Cuddihy RM, Bergenstal RM. Clinical application of incretin-based therapy: therapeutic potential, patient selection and clinical use. Eur J Intern Med. 2009;20(Suppl 2):S329-S339.

5. Bergenstal RM, Bailey CJ, Kendall DM. Type 2 diabetes: assessing the relative risks and benefits of glucose-lowering medications. $\mathrm{Am} \mathrm{J}$ Med. 2010;123(4):374.e379-e374. e318.

6. Perley MJ, Kipnis DM. Plasma insulin responses to oral and intravenous glucose: studies in normal and diabetic subjects. $J$ Clin Invest. 1967;46(12):1954-1962.

7. Elrick H, Stimmler L, Hlad CJ Jr, Arai Y. Plasma insulin response to oral and intravenous glucose administration. J Clin Endocrinol Metab. 1964;24:1076-1082.

8. Drucker DJ. The biology of incretin hormones. Cell Metab. 2006;3(3): $153-165$

9. Holst JJ. The physiology of glucagon-like peptide 1. Physiol Rev. 2007;87(4):1409-1439.

10. Nauck MA, Niedereichholz U, Ettler R, et al. Glucagon-like peptide 1 inhibition of gastric emptying outweighs its insulinotropic effects in healthy humans. Am J Physiol. 1997;273(5 Pt 1):E981-E988.

11. Tang-Christensen M, Larsen PJ, Göke R, et al. Central administration of GLP-1-(7-36) amide inhibits food and water intake in rats. $\mathrm{Am} J$ Physiol. 1996;271(4 Pt 2):R848-R856.

12. Gutzwiller JP, Tschopp S, Bock A, et al. Glucagon-like peptide 1 induces natriuresis in healthy subjects and in insulin-resistant obese men. J Clin Endocrinol Metab. 2004;89(6):3055-3061.

13. Gutzwiller JP, Hruz P, Huber AR, et al. Glucagon-like peptide-1 is involved in sodium and water homeostasis in humans. Digestion. 2006;73(2-3):142-150.

14. Mudaliar S, Henry RR. Incretin therapies: effects beyond glycemic control. Eur J Intern Med. 2009;20(Suppl 2):S319-S328.

15. Mudaliar S, Henry RR. Effects of incretin hormones on beta-cell mass and function, body weight, and hepatic and myocardial function. Am J Med. 2010;123(Suppl 3):S19-S27.
16. Byetta [package insert]. San Diego, CA: Amylin Pharmaceuticals, LLC; 2011.

17. Victoza [package insert]. Bagsvaerd, Denmark: Novo Nordisk A/S; 2011.

18. Bydureon [package insert]. San Diego, CA: Amylin Pharmaceuticals, LLC; 2012.

19. Deacon CF, Johnsen AH, Holst JJ. Degradation of glucagon-like peptide-1 by human plasma in vitro yields an $\mathrm{N}$-terminally truncated peptide that is a major endogenous metabolite in vivo. J Clin Endocrinol Metab. 1995;80(3):952-957.

20. Januvia [package insert]. Whitehouse Station, NJ: Merck and Co, Inc; 2007.

21. Onglyza [package insert]. Princeton, NJ: Bristol-Myers Squibb Company; 2011.

22. Tradjenta [package insert]. Ridgefield, CT: Boehringer Ingelheim Pharmaceuticals, Inc; 2011.

23. European Medicines Agency. Vildagliptin: summary of product characteristics. Available from: http://www.ema.europa.eu/docs/en GB/document_library/EPAR___Product_Information/human/000771/ WC500020327.pdf. Accessed Jun 2012.

24. Lovshin JA, Drucker DJ. Incretin-based therapies for type 2 diabetes mellitus. Nat Rev Endocrinol. 2009;5(5):262-269.

25. Cersosimo E, Gastaldelli A, Cervera A, et al. Effect of exenatide on splanchnic and peripheral glucose metabolism in type 2 diabetic subjects. J Clin Endocrinol Metab. 2011;96(6):1763-1770.

26. Cervera A, Wajcberg E, Sriwijitkamol A, et al. Mechanism of action of exenatide to reduce postprandial hyperglycemia in type 2 diabetes. Am J Physiol Endocrinol Metab. 2008;294(5):E846-E852.

27. Kolterman OG, Buse JB, Fineman MS, et al. Synthetic exendin-4 (exenatide) significantly reduces postprandial and fasting plasma glucose in subjects with type 2 diabetes. J Clin Endocrinol Metab. 2003;88(7):3082-3089.

28. DeYoung MB, MacConell L, Sarin V, Trautmann M, Herbert P. Encapsulation of exenatide in poly-(D,L-lactide-co-glycolide) microspheres produced an investigational long-acting once-weekly formulation for type 2 diabetes. Diabetes Technol Ther. 2011;13(11): $1145-1154$.

29. Anderson JM, Shive MS. Biodegradation and biocompatibility of PLA and PLGA microspheres. Adv Drug Deliv Rev. 1997;28(1):5-24.

30. Lewis DH. Controlled release of bioactive agents from lactide/glycolide polymers. In: Chasin M, Langer RS, editors. Biodegradable Polymers as Drug Delivery Systems. New York: Marcel Dekker; 1990:1-41.

31. Vivitrol [package insert]. Waltham, MA: Alkermes, Inc; 2010.

32. Fineman M, Flanagan S, Taylor K, et al. Pharmacokinetics and pharmacodynamics of exenatide extended-release after single and multiple dosing. Clin Pharmacokinet. 2011;50(1):65-74.

33. Bergenstal RM, Wysham C, MacConell L, et al. Efficacy and safety of exenatide once weekly versus sitagliptin or pioglitazone as an adjunct to metformin for treatment of type 2 diabetes (DURATION-2): a randomised trial. Lancet. 2010;376(9739):431-439.

34. Blevins T, Pullman J, Malloy J, et al. DURATION-5: exenatide once weekly resulted in greater improvements in glycemic control compared with exenatide twice daily in patients with type 2 diabetes. $J$ Clin Endocrinol Metab. 2011;96(5):1301-1310.

35. Diamant M, Van Gaal L, Stranks S, et al. Once weekly exenatide compared with insulin glargine titrated to target in patients with type 2 diabetes (DURATION-3): an open-label randomised trial. Lancet. 2010;375(9733):2234-2243.

36. Drucker DJ, Buse JB, Taylor K, et al. Exenatide once weekly versus twice daily for the treatment of type 2 diabetes: a randomised, open-label, non-inferiority study. Lancet. 2008;372(9645): $1240-1250$.

37. Russell-Jones D, Cuddihy RM, Hanefeld M, et al. Efficacy and safety of exenatide once weekly versus metformin, pioglitazone, and sitagliptin used as monotherapy in drug-naive patients with type 2 diabetes (DURATION-4): a 26-week double-blind study. Diabetes Care. 2012;35(2):252-258. 
38. Buse JB, Nauck M, Forst T, et al. Exenatide once weekly versus liraglutide in patients with type 2 diabetes (DURATION-6): a randomised, open-label study. Lancet. 2013;381(9861):117-124.

39. Wysham C, Bergenstal R, Malloy J, et al. DURATION-2: efficacy and safety of switching from maximum daily sitagliptin or pioglitazone to once-weekly exenatide. Diabet Med. 2011;28(6):705-714.

40. MacConell L, Brown C, Gurney K, Han J. Safety and tolerability of exenatide twice daily in patients with type 2 diabetes: integrated analysis of 5594 patients from 19 placebo-controlled and comparator-controlled clinical trials. Diabetes Metab Syndr Obes. 2012;5:29-41.

41. Fineman MS, Shen LZ, Taylor K, Kim DD, Baron AD. Effectiveness of progressive dose-escalation of exenatide (exendin-4) in reducing dose-limiting side effects in subjects with type 2 diabetes. Diabetes Metab Res Rev. 2004;20(5):411-417.

42. Amylin Pharmaceuticals. Exenatide tQT study showed no prolongation of QT interval [press release]. San Diego: Amylin Pharmaceuticals; July 7, 2011. Available from: http://phx.corporate-ir.net/phoenix. zhtml?c=101911\&p=irol-newsArticle \&ID=1583328. Accessed May 2012.

43. Sager P, Darpö B, Han J, et al. Exenatide once weekly did not affect corrected QT interval in patients with type 2 diabetes. Diabetes. 2011;60:A294.

44. Linnebjerg H, Seger M, Kothare PA, Hunt T, Wolka AM, Mitchell MI. A thorough QT study to evaluate the effects of singledose exenatide $10 \mathrm{mcg}$ on cardiac repolarization in healthy subjects. Int J Clin Pharmacol Ther. 2011;49(10):594-604.

45. Buse JB, Drucker DJ, Taylor KL, et al. DURATION-1: exenatide once weekly produces sustained glycemic control and weight loss over 52 weeks. Diabetes Care. 2010;33(6):1255-1261.

46. Elashoff M, Matveyenko AV, Gier B, Elashoff R, Butler PC. Pancreatitis, pancreatic, and thyroid cancer with glucagon-like peptide-1-based therapies. Gastroenterology. 2011;141(1):150-156.

47. Drucker DJ, Sherman SI, Bergenstal RM, Buse JB. The safety of incretin-based therapies - review of the scientific evidence. J Clin Endocrinol Metab. 2011;96(7):2027-2031.

48. Dore DD, Seeger JD, Arnold Chan K. Use of a claims-based active drug safety surveillance system to assess the risk of acute pancreatitis with exenatide or sitagliptin compared to metformin or glyburide. Curr Med Res Opin. 2009;25(4):1019-1027.
49. Giovannucci E, Harlan DM, Archer MC, et al. Diabetes and cancer: a consensus report. Diabetes Care. 2010;33(7):1674-1685.

50. Bjerre Knudsen L, Madsen LW, Andersen S, et al. Glucagon-like peptide-1 receptor agonists activate rodent thyroid $\mathrm{C}$-cells causing calcitonin release and C-cell proliferation. Endocrinology. 2010;151(4): 1473-1486.

51. Hegedus L, Moses AC, Zdravkovic M, Le Thi T, Daniels GH. GLP-1 and calcitonin concentration in humans: lack of evidence of calcitonin release from sequential screening in over 5000 subjects with type 2 diabetes or nondiabetic obese subjects treated with the human GLP-1 analog, liraglutide. J Clin Endocrinol Metab. 2011;96(3):853-860.

52. MacConell L, Malloy J, Huang W, Cirincione B, Shen L, Porter L. Safety and efficacy of once-monthly exenatide over 20 weeks in patients with type 2 diabetes. Diabetologia. 2011;54:S38.

53. Rubin RR. Adherence to pharmacologic therapy in patients with type 2 diabetes mellitus. Am J Med. 2005;118(Suppl 5A):27S-34S.

54. Saini SD, Schoenfeld P, Kaulback K, Dubinsky MC. Effect of medication dosing frequency on adherence in chronic diseases. Am J Manag Care. 2009;15(6):e22-e33.

55. Luskey L, Rosenstock J, Alessi T, Henry RR. Long-term, injectionfree treatment with ITCA 650, a continuous subcutaneous delivery of exenatide via DUROS ${ }^{\circledR}$ device, leads to stable glycaemic and weight control for 48 weeks in metformin-treated type 2 diabetes. Diabetologia. 2011;54(Suppl 1):S39.

56. Inzucchi SE, Bergenstal RM, Buse JB, et al. Management of hyperglycemia in type 2 diabetes: a patient-centered approach: position statement of the American Diabetes Association (ADA) and the European Association for the Study of Diabetes (EASD). Diabetes Care. 2012;35(6):1364-1379.

57. Lorenzi G, Schreiner B, Osther J, Boardman M. Application of adultlearning principles to patient instructions: a usability study for an exenatide once-weekly injection device. Clin Diabetes. 2010;28(4): 157-162.

58. Taylor K, Kim D, Nielsen LL, Aisporna M, Baron AD, Fineman MS. Day-long subcutaneous infusion of exenatide lowers glycemia in patients with type 2 diabetes. Horm Metab Res. 2005;37(10):627-632.

\section{Publish your work in this journal}

Diabetes, Metabolic Syndrome and Obesity: Targets and Therapy is an international, peer-reviewed open-access journal committed to the rapid publication of the latest laboratory and clinical findings in the fields of diabetes, metabolic syndrome and obesity research. Original research, review, case reports, hypothesis formation, expert opinion and commentaries are all considered for publication. The manuscript management system is completely online and includes a very quick and fair peer-review system, which is all easy to use. Visit http://www.dovepress.com/testimonials.php to read real quotes from published authors. 